\title{
Improved electromechanical stability of Li metal/garnet ceramic interface by a solvent-free deposited OIPC soft layer
}

Antonio Gutiérrez-Pardo, ${ }^{1 *}$ Frédéric Aguesse, ${ }^{1}$ Francisco Fernández-Carretero, ${ }^{2}$ Amal $I$. Siriwardana, ${ }^{2}$ Alberto García-Luis, ${ }^{2}$ Anna Llordés. ${ }^{1,3 *}$

${ }^{1}$ Centre for Cooperative Research on Alternative Energies (CIC energiGUNE), Basque Research and Technology Alliance (BRTA), Alava Technology Park, Albert Einstein 48, 01510 Vitoria-Gasteiz, Spain.

2 TECNALIA, Basque Research and Technology Alliance (BRTA), Mikeletegi Pasealekua 2, 20009 Donostia-San Sebastián, Spain.

3 IKERBASQUE, The Basque Foundation for Science, María Díaz de Haro 3, 48013 Bilbao, Spain

*Corresponding authors: agutierrez@cicenergigune.com; allordes@fuelium.tech

\section{SUPPORTING INFORMATION}

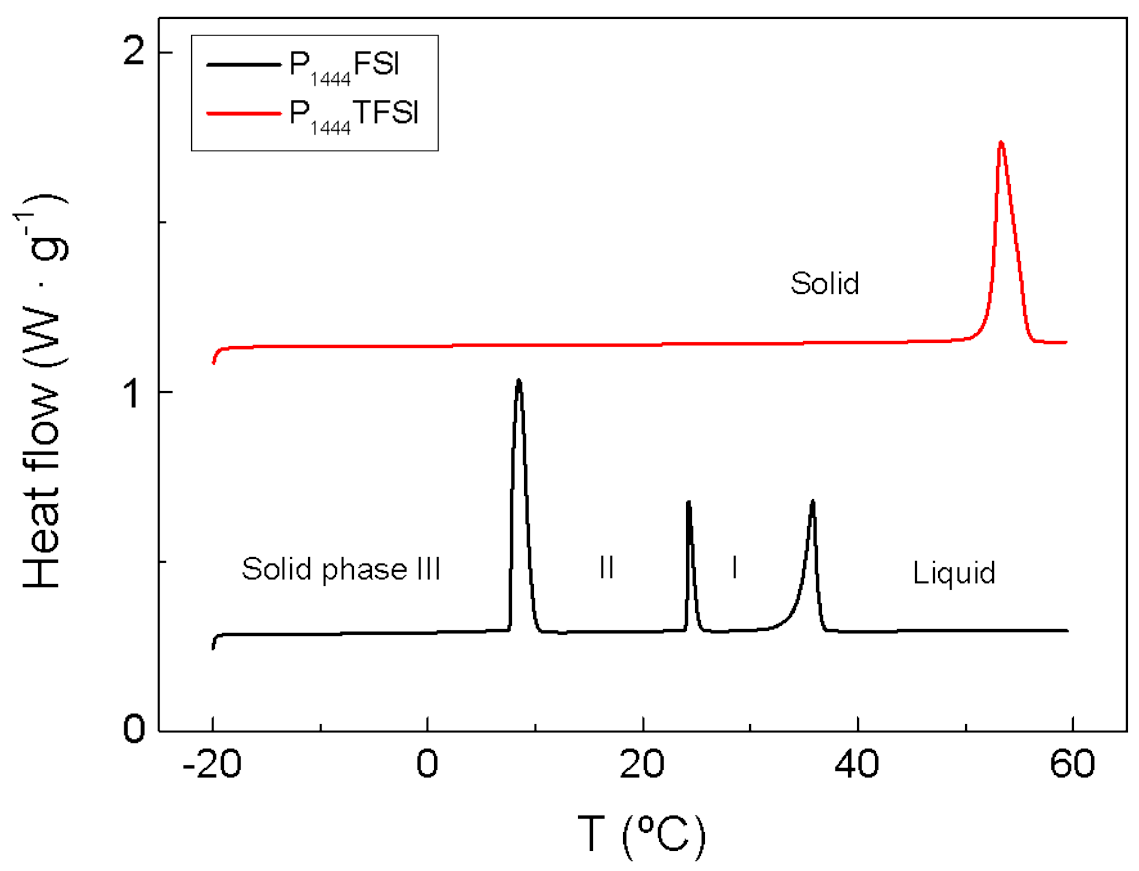

Figure S1. DSC results of $P_{1444} F S I$ (OIPC) and $P_{1444} T F S I$ (non-OIPC). 
Table S1. Transition temperatures and entropy of OIPC samples, before and after LiTFSI addition.

\begin{tabular}{|c|c|c|c|c|c|c|}
\hline \multirow[t]{2}{*}{ Sample } & \multicolumn{2}{|c|}{ III to II } & \multicolumn{2}{|c|}{ II to I } & \multicolumn{2}{|c|}{ I to melt } \\
\hline & $\begin{array}{c}\text { Temperature } \\
(\stackrel{\circ}{ })\end{array}$ & $\begin{array}{l}\text { Entropy } \\
\left(\mathrm{Jmol}^{-1} \mathrm{~K}^{-1}\right)\end{array}$ & $\begin{array}{l}\text { Temperature } \\
\qquad(\stackrel{\circ}{ } \mathrm{C})\end{array}$ & $\begin{array}{l}\text { Entropy } \\
\left(\mathrm{Jmol}^{-1} \mathrm{~K}^{-1}\right)\end{array}$ & $\begin{array}{c}\text { Temperature } \\
(\stackrel{\circ}{ } \mathrm{C})\end{array}$ & $\begin{array}{l}\text { Entropy } \\
\left(\mathrm{Jmol}^{-1} \mathrm{~K}^{-1}\right)\end{array}$ \\
\hline $\begin{array}{c}\mathbf{P}_{14444} \mathrm{FSI} \\
\text { (no LiTFSI) }\end{array}$ & 8.5 & 46.3 & 24.2 & 10.7 & 35.8 & 22.9 \\
\hline$P_{1444}$ TFSI & - & - & - & - & 53.3 & 59.5 \\
\hline$P_{1444} \mathrm{FSI}$ & 8.9 & 38.7 & 24.3 & 11.0 & 27.9 & * \\
\hline $\begin{array}{c}\text { H5 } \\
\text { (no LiTFSI) }\end{array}$ & 9.0 & 49.2 & 24.5 & 11.3 & 36.6 & 25.0 \\
\hline $\begin{array}{c}\text { H10 } \\
\text { (no LiTFSI) }\end{array}$ & 7.7 & 47.2 & 24.9 & 9.8 & 33.2 & 9.6 \\
\hline H10 & 9.1 & 40.1 & & & 23.1 & 10.3 \\
\hline $\begin{array}{c}\text { H2O } \\
\text { (no LiTFSI) }\end{array}$ & 8.1 & 58.2 & & & 21.1 & 8.5 \\
\hline $\mathrm{H} 2 \mathrm{O}$ & 9.3 & 42.9 & & & 24.0 & 15.3 \\
\hline
\end{tabular}

The table shows the transition temperatures and the entropy of samples, before and after salt addition. The phase nomenclature used is described by Chezeau et al., ${ }^{1}$ where the highest temperature solid phase is named phase $\mathrm{I}$. When a $5 \%$ of $\mathrm{P}_{1444} \mathrm{TFSI}$ is incorporated into the crystalline structure of $\mathrm{P}_{1444} \mathrm{FSI}$, a slight increase of the entropy of the three thermal transitions is evidenced. When the amount of $\mathrm{P}_{1444}$ TFSI is increased up to $10 \mathrm{wt} . \%$, the thermal behaviour significantly changes, leading to the formation of an amorphous phase which does not take part in the thermal transition. As a consequence, the overall entropy and the melting temperature decrease respect to the pure $\mathrm{P}_{1444} \mathrm{FSI}$.

* Entropy is not included due to poorly defined peak. H5 data is included in order to understand and support experimentally the thermal behaviour of the $\mathrm{P}_{1444} \mathrm{FSI}$ with the $\mathrm{P}_{1444}$ TFSI addition.

1. Chezeau, J. M. \& Strange, J. H. Diffusion in molecular crystals. Phys. Rep. 53, 1-92 (1979). 
(a)

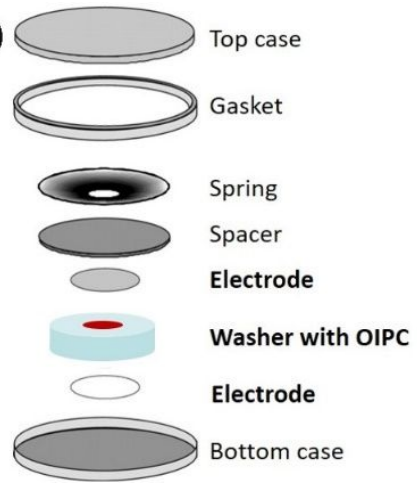

(b) Temperature $\left({ }^{\circ} \mathrm{C}\right)$

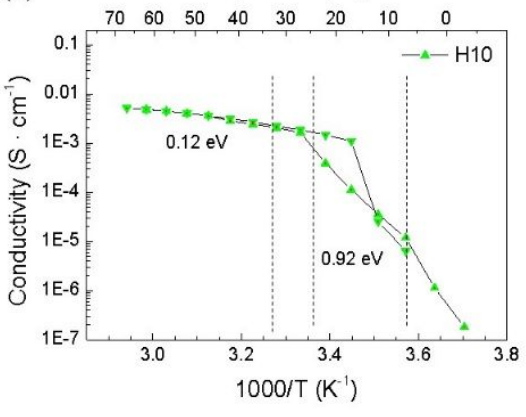

Temperature $\left({ }^{\circ} \mathrm{C}\right)$

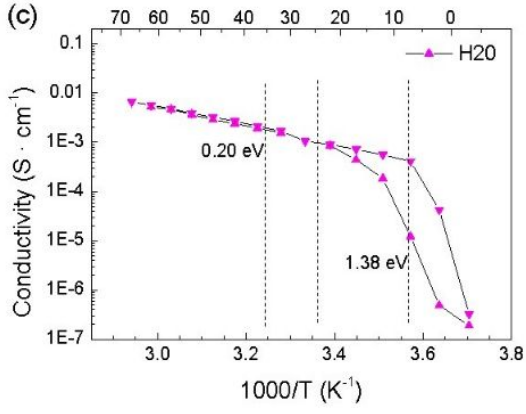

Figure S2. (a) Coin cell configuration to perform conductivity measurements of OIPCs as electrolytes by themselves. Arrhenius plots of OIPCs (b) $\mathrm{H} 10$ and (c) $\mathrm{H} 2 \mathrm{O}$.

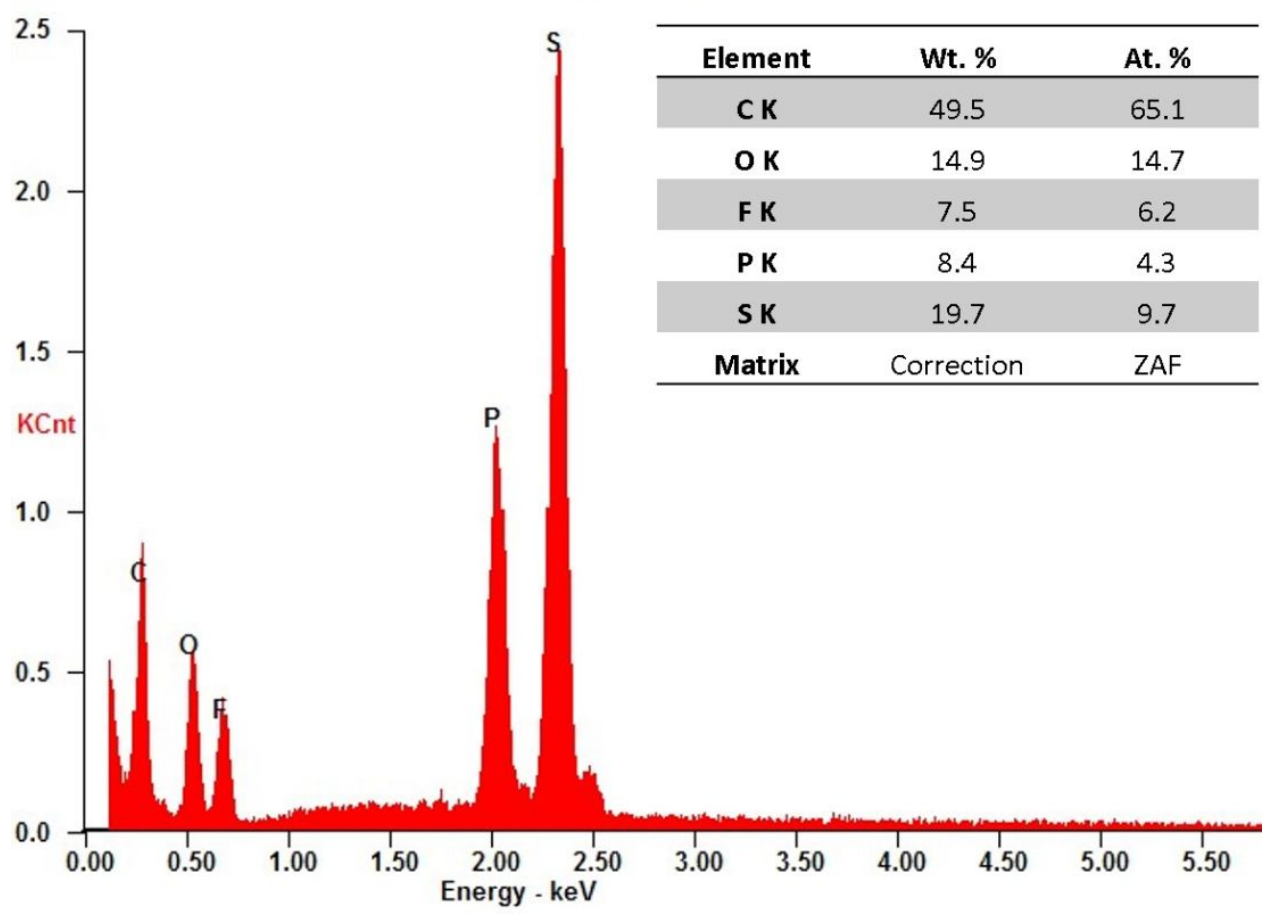

Figure S3. Spectrum representative of the EDS measurement recorded at the surface of a Li foil coated with OIPC H10, and quantification of the reported elements. 

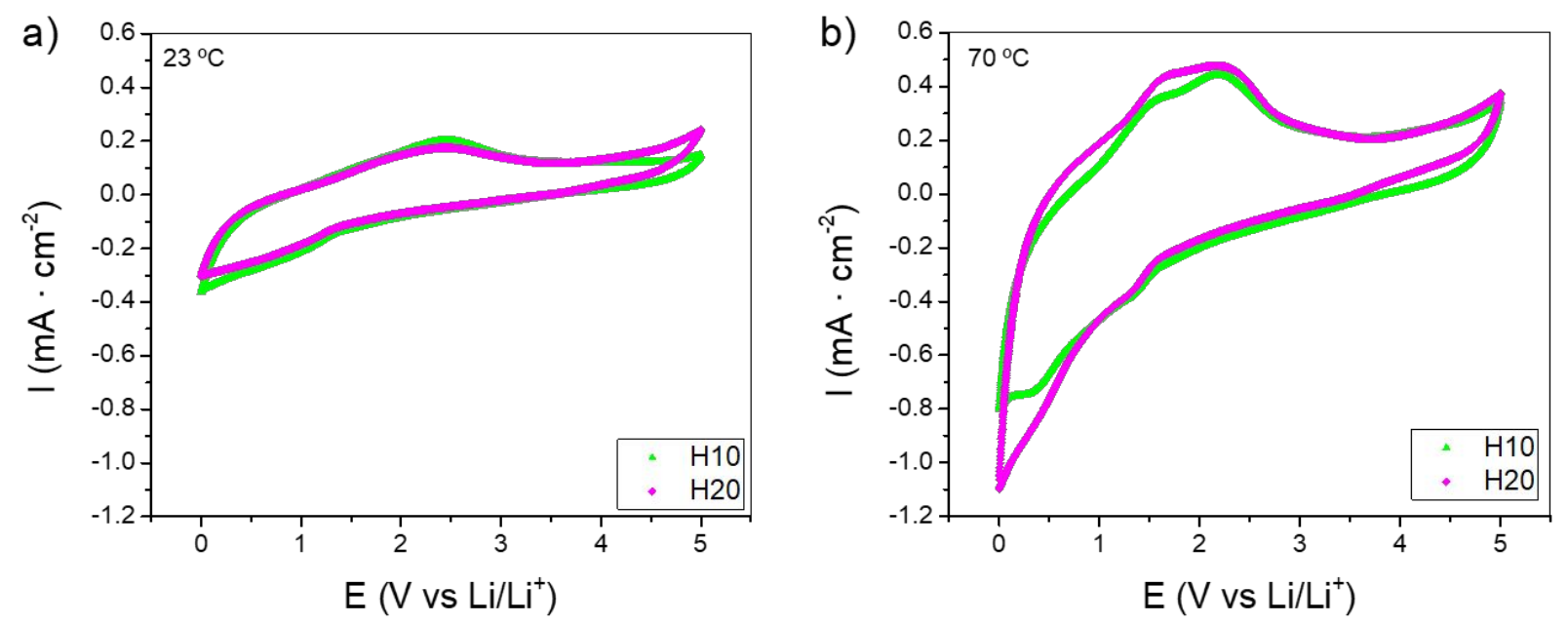

Fig. S4. Cyclic voltammograms of $\mathrm{H} 10$ and $\mathrm{H} 20$ samples, with a scan rate of $0.02 \mathrm{mV} \cdot \mathrm{s}^{-1}$, at (a) room temperature, (b) $70^{\circ} \mathrm{C}$. Working and reference/counter electrode were both Li metal.

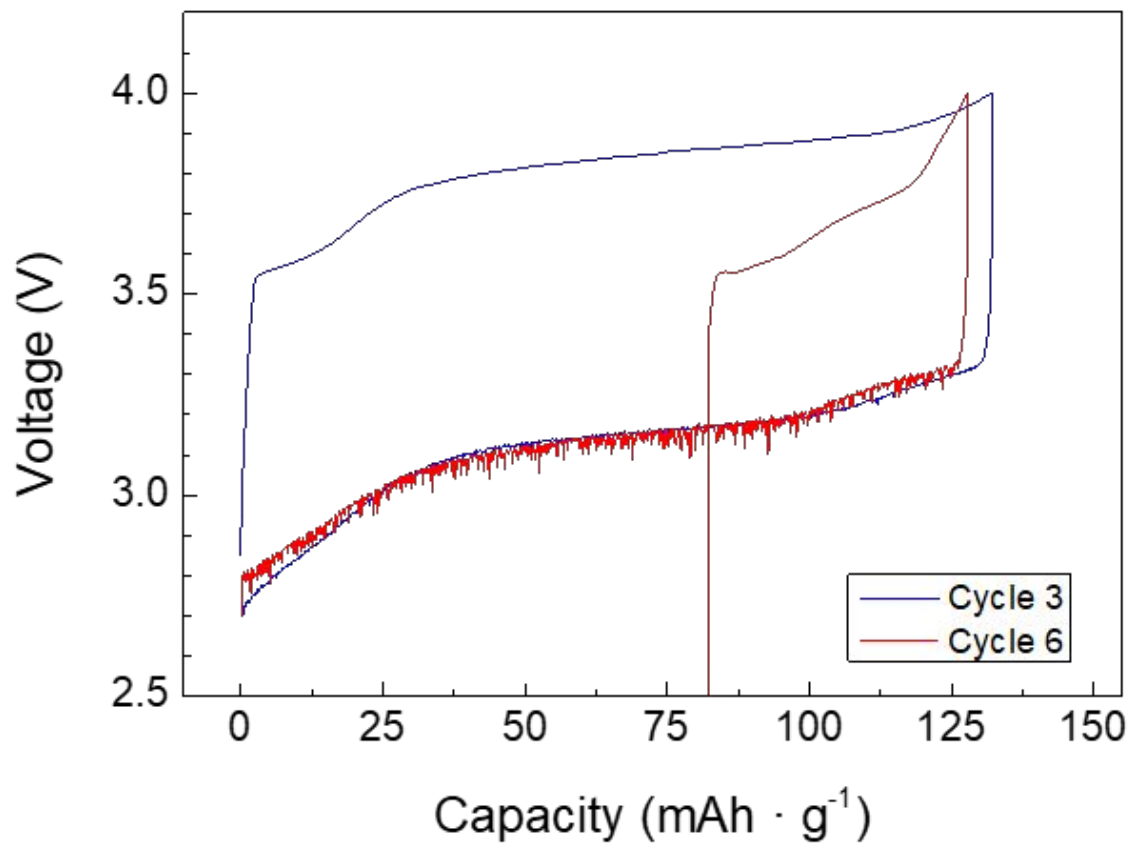

Figure S5. Galvanostatic charge and discharge curves of the full cell at different cycle numbers. 


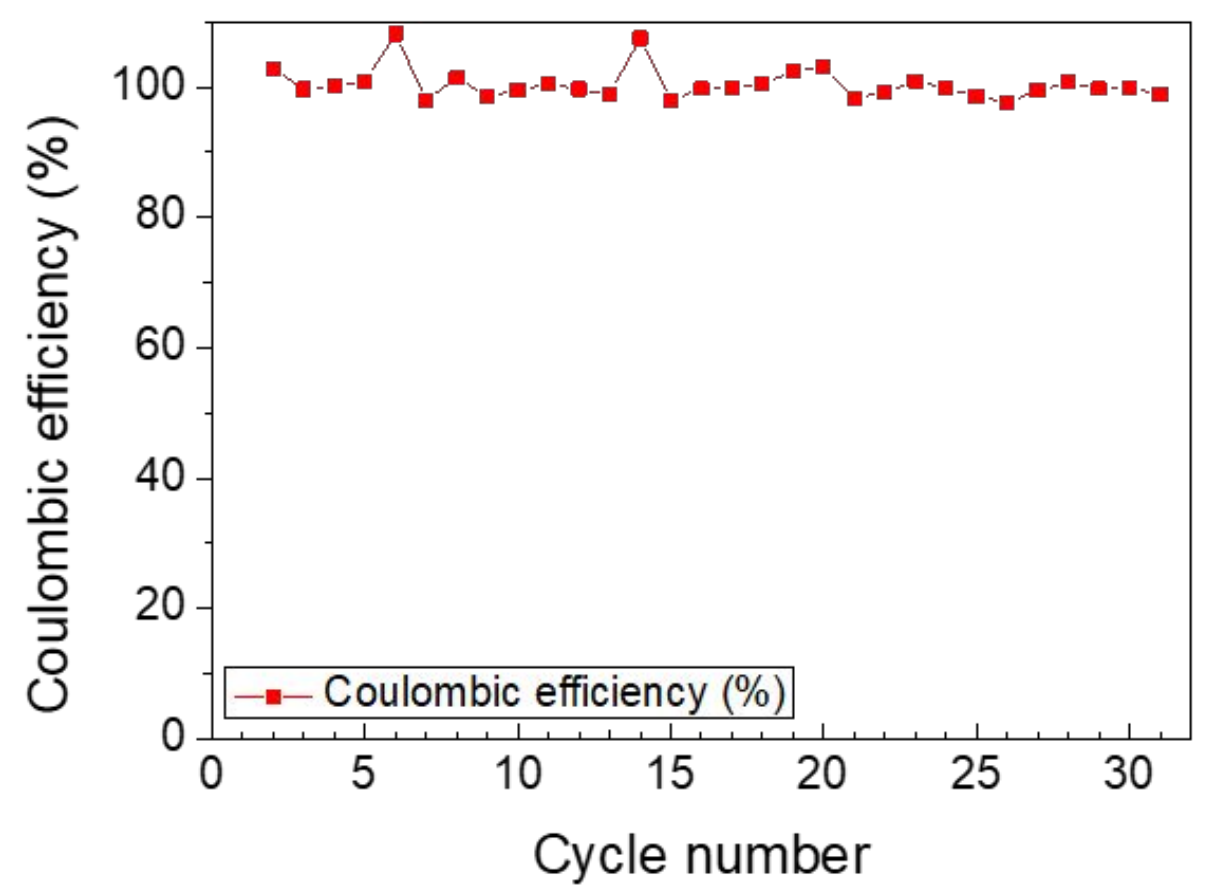

Fig. S6. Coulombic efficiency of the full cell LFP/OIPC-LLZO-OIPC/Li.

Table S2. Relevant electrochemical results obtained in this study.

\begin{tabular}{|c|c|c|c|}
\hline Sample & $\begin{array}{l}\text { Conductivity at RT } \\
\left(10^{-3} \mathrm{~S} \cdot \mathrm{cm}^{-1}\right)\end{array}$ & $E_{a}(e V)$ & $\begin{array}{l}\text { ASR at RT } \\
\left(\Omega \cdot \mathrm{cm}^{2}\right)\end{array}$ \\
\hline LLZO & $0.42 \pm 0.05$ & 0.44 & $640 \pm 160$ \\
\hline LLZO + H10 & $1.0 \pm 0.1$ & 0.40 & $130 \pm 20$ \\
\hline LLZO + H2O & $1.1 \pm 0.2$ & 0.44 & $120 \pm 50$ \\
\hline H10 & 1.9 & $\begin{array}{l}0.12>27^{\circ} \mathrm{O} C \\
0.92<27^{\circ} \mathrm{C} C\end{array}$ & \\
\hline $\mathrm{H} 2 \mathrm{O}$ & 1.6 & $\begin{array}{l}0.20>22^{\circ} \mathrm{C} \\
1.38<22{ }^{\circ} \mathrm{C}\end{array}$ & \\
\hline
\end{tabular}

